\title{
Electrophysiological differences in the processing of affective information in words and pictures
}

\author{
José A. Hinojosa \\ Universidad Complutense de Madrid, Madrid, Spain \\ LUIS CARRETIÉ \\ Universidad Autónoma de Madrid, Madrid, Spain \\ AND \\ María A. ValcárCel, Constantino Méndez-Bértolo, And Miguel A. Pozo
Universidad Complutense de Madrid, Madrid, Spain
}

It is generally assumed that affective picture viewing is related to higher levels of physiological arousal than is the reading of emotional words. However, this assertion is based mainly on studies in which the processing of either words or pictures has been investigated under heterogenic conditions. Positive, negative, relaxing, neutral, and background (stimulus fragments) words and pictures were presented to subjects in two experiments under equivalent experimental conditions. In Experiment 1, neutral words elicited an enhanced late positive component (LPC) that was associated with an increased difficulty in discriminating neutral from background stimuli. In Experiment 2, high-arousing pictures elicited an enhanced early negativity and LPC that were related to a facilitated processing for these stimuli. Thus, it seems that under some circumstances, the processing of affective information captures attention only with more biologically relevant stimuli. Also, these data might be better interpreted on the basis of those models that postulate a different access to affective information for words and pictures.

Usually, two main types of visual emotional stimuli have been employed in the study of affect-related processes: verbal (e.g., single words or sentences) and pictorial (e.g., facial expressions or emotional scenes). An important and recurrent question is whether both types of visual stimuli are equally capable of inducing emotional reactions. Some authors have pointed out that pictorial stimuli are associated with higher levels of emotional arousal than is verbal emotional material (Carretié et al., 2008; Keil, 2006; Kissler, Assadollahi, \& Herbert, 2006; Mogg \& Bradley, 1998). On the one hand, these assertions are based in part on theoretical views that deny any role for verbal material in the evolution of emotion-related neural systems and assume that the processing of verbal material is culture mediated. On the other hand, such assertions are based on indirect evidence provided by the results of several studies that have dealt with the processing of verbal or pictorial emotional stimuli separately, across a wide variety of tasks and experimental parameters.

The situation becomes still more problematic when differences in the stimulus channel during the processing of verbal and pictorial stimuli are considered. Some authors have claimed that meaning is represented in a functional unitary system that is directly accessed by both visual objects and words (Caramazza, 1996). However, an alterna- tive theoretical perspective (e.g., Glaser, 1992; Glaser \& Glaser, 1989) postulates a distinction between a semantic system involved in the perception of images, which contains only semantic knowledge, and a lexicon that is responsible for language perception, which includes only linguistic knowledge. On this view, pictures have a privileged access to all nodes of the semantic system, because language perception comprises additional processing before accessing the semantic system. On the basis of these models, some theories of affect state that affective information is stored as a sort of tag, associated with the concept node within a network similar to the semantic system (Bower, 1981; Fazio, Sanbonmatsu, Powell, \& Kardes, 1986; Fiske \& Pavelchak, 1986). According to this view, pictures would show a facilitated access to emotional aspects (De Houwer \& Hermans, 1994).

\section{Studies Comparing Words and Pictures}

Only two previous studies have directly compared the processing of emotional words and pictures (see also Vanderploeg, Brown, \& Marsh, 1987, for a comparison between words and schematic drawings of faces). In the first of these studies, De Houwer and Hermans (1994) used a word-picture affective Stroop task and found that emotional pictures, but not words, produced interference 
effects. Also, naming times were reduced for negative pictures, but not for negative words. These authors concluded that pictures have privileged access to emotional information. In an fMRI study, Kensinger and Schacter (2006) presented positive, negative, and neutral words and pictures that subjects had to rate as to whether they described something animate or inanimate or something common or uncommon. They found that the processing of both emotional words and pictures enhanced the activity of the amygdala and several regions of the prefrontal and anterior temporal cortex. In general, these effects were more pronounced in the case of pictures. Even though these studies reveal interesting aspects of the contribution of distinct brain areas to the processing of the emotional aspects of words and pictures and address other general questions, they say little about the temporal aspects involved in the processing of the affective information in words and pictures, due to the temporal limitations of the fMRI and behavioral measures. In the present study, our aim was to resolve this issue by using event-related potentials (ERPs), which are particularly well suited for studying the temporal characteristics of emotional processes.

\section{ERP Studies of Affective Processing in Words and Pictures}

Studies with ERPs that have used either words or images with affective content as stimuli have revealed that the processing of emotional information modulates brain activity at different temporal stages and scalp locations. One of the most consistent findings has been the enhancement of late positivities at centro-parietal locations (the P300, or late positive component [LPC]), by positive and negative stimuli, as compared with neutral ones, by either images (e.g., Cuthbert, Schupp, Bradley, Birbaumer, \& Lang, 2000; Delplanque, Silvert, Hot, Rigoulot, \& Sequeira, 2006; Keil et al., 2002; Olofsson \& Polich, 2007; see Olofsson, Nordin, Sequeira, \& Polich, 2008, for a review) or words (e.g., Carretié et al., 2008; Dillon, Cooper, Grent-'t-Jong, Woldorff, \& LaBar, 2006; Herbert, Kissler, Junghöfer, Peyk, \& Rockstroh, 2006; Kanske \& Kotz, 2007; Naumann, Bartussek, Diedrich, \& Laufer, 1992). However, this modulation seems to be not unequivocal in the case of words, since several studies failed to report amplitude differences (Naumann, Maier, Diedrich, Becker, \& Bartussek, 1997; Schapkin, Gusev, \& Kuhl, 2000). The amplitude of the LPC has been thought to reflect the functional mobilization of attentional resources and the activation of the motivational circuits in the brain that mediate emotional engagement (Bradley \& Lang, 2007; Schupp et al., 2007). The LPC is especially sensitive to the level of arousal of the stimulus, since higharousing stimuli are associated to enhance amplitudes, as compared with low-arousing stimuli (Olofsson et al., 2008).

Also, a common finding of those studies in which images have been presented briefly and at high rates of stimulation has been an enhancement of the amplitude of an early posterior negativity for emotional pictures (Junghöfer,
Bradley, Elbert, \& Lang, 2001; Schupp, Junghöfer, Weike, \& Hamm, 2003, 2004) and words (Kissler, Herbert, Peyk, \& Junghöfer, 2007), as compared with neutral stimuli. It is not clear whether this component is sensitive to valence, arousal, or both aspects. In this regard, some studies have reported that high-arousing stimuli elicited larger amplitudes than did low-arousing stimuli (Junghöfer et al., 2001; Kissler, Herbert, et al., 2007), whereas others have shown that positive stimuli were associated to enhanced amplitudes, as compared with negative stimuli (Schupp et al., 2004). On the basis of these inconsistent results, the early negativity has been thought to reflect general initial phases of attention and evaluative processes during access to affective information.

\section{The Present Study}

Overall, it seems that words and pictures with emotional content are able to significantly modulate brain activity. However, the lack of studies comparing the processing of affective information in words and pictures makes it difficult to figure out how electrophysiological data can accommodate any of the alternative theoretical views. The aim of our study was thus to directly compare the processing of emotional words and pictures through the analysis of electrophysiological (ERPs) and behavioral (reaction times [RTs]) indices. Since words and pictures are difficult to equate in their physical attributes, we decided to present them in two separate experiments with equivalent parameters, instead of merging words and pictures in the same experiment.

The experimental design selected for our purposes is a critical issue, since temporal and topographical features of the ERPs depend strongly on such issues as task requirements and stimuli duration. We opted to use an indirect task and a high rate of stimulation. In our task, subjects had to discriminate between senseless and nonsenseless stimuli. Nonindirect tasks (i.e., subjects are asked to perform an affective categorization of the stimuli) might lead subjects to consider that some stimuli are more important than others (i.e., emotional, salient stimuli might be more important than neutral ones for an experiment on emotional reactions). This cognitive interference overlaps with affective effects (Carretié, Hinojosa, Albert, \& Mercado, 2006; Carretié, Hinojosa, Martín-Loeches, Mercado, \& Tapia, 2004). Indeed, the ERPs elicited by emotional stimuli in direct tasks are different from those elicited in indirect tasks (Carretié, Iglesias, García, \& Ballesteros, 1997). Also, the stimuli were presented at high rates with the purpose of exploring the early emotional processes indexed by the early posterior negativity.

We expected that both emotional words and pictures elicit two components: an early negativity and a late positivity. This allowed us to answer two important questions. First, can affective information be accessed equally by words and pictures? Second, are pictures more "affectively powerful" stimuli than words? Regarding the first question, according to those models that assume a distinct access to affective information for words and pictures (Fiske \& Pavelchak, 1986), a different modulation 
of the early component by emotional words and pictures would be expected. However, a similar modulation of the early negativity would suggest that affective information is accessed equally by words and pictures. This finding would be in line with the proposal of a unitary semantic system (Caramazza, 1996). Also, distinct modulation of the pattern of RTs by emotional words and pictures could be taken to support the functional segregation perspective, whereas a similar modulation of RTs by both types of stimuli would be interpreted better in light of the unitary system proposal.

Regarding the second question, the early negativity has been shown not to be unequivocally modulated by arousal manipulations (Schupp et al., 2004). However, the late positivity has repeatedly been shown to be especially sensitive to arousal aspects of the stimuli (Olofsson \& Polich, 2007). A greater modulation of the amplitude of this component by affective pictures, as compared with emotional words, would support the statement that images are associated to higher degrees of physiological arousal (Lang, Bradley, \& Cuthbert, 1998).

\section{EXPERIMENT 1}

\section{Method}

Subjects. Twenty native Spanish speakers (19 women) participated in the experiment as volunteers. Their mean age was 21 years (ranging from 19 to 27 years), and they all were right-handed according to the Edinburgh Handedness Inventory (Oldfield, 1971). All the subjects reported normal or corrected-to-normal visual acuity.

Stimuli. For the purpose of exploring both valence (negative to positive) and arousal (calming to arousing) dimensions, stimuli belonged to four different categories: negative, positive, neutral, and relaxing. Eighty nouns (20 positive, 20 negative, 20 relaxing, and 20 neutral), together with 80 background stimuli, were used for experimental purposes. Background stimuli were made by cutting the 80 words into several portions. These portions were combined randomly, resulting in nonsense stimuli resembling the physical attributes of the words (size, color, brightness, etc.). All the stimuli were presented black-on-white on a computer monitor, controlled by the Gentask module of the STIM2 package (NeuroScan Inc.).

In a previous phase, a 720 -word list that included positive, negative, relaxing, and neutral nouns, divided into three sets ( 240 words each) was assessed by 45 ( 15 for each set) subjects (different from those who participated in Experiment 1), who rated the valence, arousal, and concreteness of each word on a 9-point scale ( 9 being very positive, very activating, and very concrete, respectively). The
720 words were divided into three sets due to the great amount of time that would be necessary to assess all words as a single sample. In the end, the words that were employed in Experiment 1 were selected according to several criteria contrasted with one-way ANOVAs and post hoc analyses with the Bonferroni correction $(p<.05)$. Positive and negative words were matched in arousal and differed in valence. Relaxing words were matched to positive words in valence but differed in arousal and differed in both valence and arousal from negative words. Neutral words differed from each other word type in both valence and arousal. All the nouns were matched in frequency of use in Spanish [Alameda \& Cuetos, 1995; 92 positive words, 86 negative words, 98 neutral words, and 91 relaxing words; $F(3,57)=0.02, p>.05]$. In addition, all the nouns were equated in word length [3.2 syllables for positive words, 3.2 syllables for negative words, 3 for neutral words, and 2.7 for relaxing words; $F(3,57)=1.2, p>.05$ ] and had similar ratings on the concreteness scale [ 6.4 for positive words, 6.7 for negative words, 6.5 for neutral words, 6.7 for relaxing words; $F(3,57)=0.22, p>$ $.05]$. Table 1 summarizes mean ratings for each word emotion category on the arousal and valence dimensions, as well as the results of the ANOVAs.

Procedure. The subjects performed an indirect task. They had to discriminate meaningful words embedded in a sequence of nonsense stimuli by pressing a button as quickly as possible every time a word was detected.

Figure 1A exemplifies the procedure. The stimuli were arranged in eight sequences and were presented according to the rapid stream stimulation procedure (Hinojosa, Martín-Loeches, et al., 2001; Rudell, 1992). This procedure speeds up stimuli processing by presenting them at a very high rate (with a stimulus onset asynchrony of $250 \mathrm{msec}$ ). In each of these sequences, the computer displayed mainly background stimuli, and after 4-7 of these stimuli (this number being randomized), a test stimulus was presented. Each sequence included 20 test stimuli ( 5 positive words, 5 negative words, 5 neutral words, and 5 relaxing words), together with the proportional amount of background stimuli. Test stimulus order was pseudorandomly determined, with the constraint that no more than 2 of the same type occurred consecutively. Each type of test stimulus was presented twice during an experimental session and was never repeated within the same sequence. A practice sequence was presented prior to the first sequence. The subjects were instructed to minimize blinking during stimulus presentation.

Data acquisition. Electroencephalographic data were recorded using an electrode cap (ElectroCap International) with tin electrodes. A total of 58 scalp locations homogeneously distributed over the scalp were used. All scalp electrodes, as well as one electrode at the left mastoid (M1), were referenced to one electrode placed at the right mastoid (M2). A bipolar horizontal and vertical electrooculogram was recorded for artifact rejection purposes. Electrode impedances were kept below $3 \mathrm{k} \Omega$. The signals were recorded continuously with a bandpass from direct current 0.1 to $50 \mathrm{~Hz}$ (3-dB

Table 1

Means for Arousal and Valence Assessments Given by the Independent Samples of Subjects for Each Word Type and Means for Arousal and Valence Assessments According to the IAPS for Each Picture Type, With the Results of the Statistical Analyses for Each of These Variables

\begin{tabular}{|c|c|c|c|c|c|}
\hline & \multicolumn{4}{|c|}{ Type } & \multirow{2}{*}{$\begin{array}{c}\text { One-Way ANOVA } \\
\text { (Affect Type) }\end{array}$} \\
\hline & Positive & Negative & Neutral & Relaxing & \\
\hline \multicolumn{6}{|l|}{ Words } \\
\hline Valence & 7.6 & 2.1 & 5.1 & 7.4 & $F(3,57)=618.6, p<.0001$ \\
\hline Arousal & 7.1 & 7.2 & 5.1 & 2.9 & $F(3,57)=984.7, p<.0001$ \\
\hline \multicolumn{6}{|l|}{ Pictures } \\
\hline Valence & 7.6 & 2.1 & 5.1 & 7.4 & $F(3,57)=121.9, p<.0001$ \\
\hline Arousal & 7.1 & 7.2 & 5.1 & 2.9 & $F(3,57)=293.1, p<.0001$ \\
\hline
\end{tabular}

Note-For arousal, $1=$ calming, $9=$ arousing; for valence, $1=$ negative $; 9=$ positive. Post hoc Bonferroni analyses are reported in the text. 

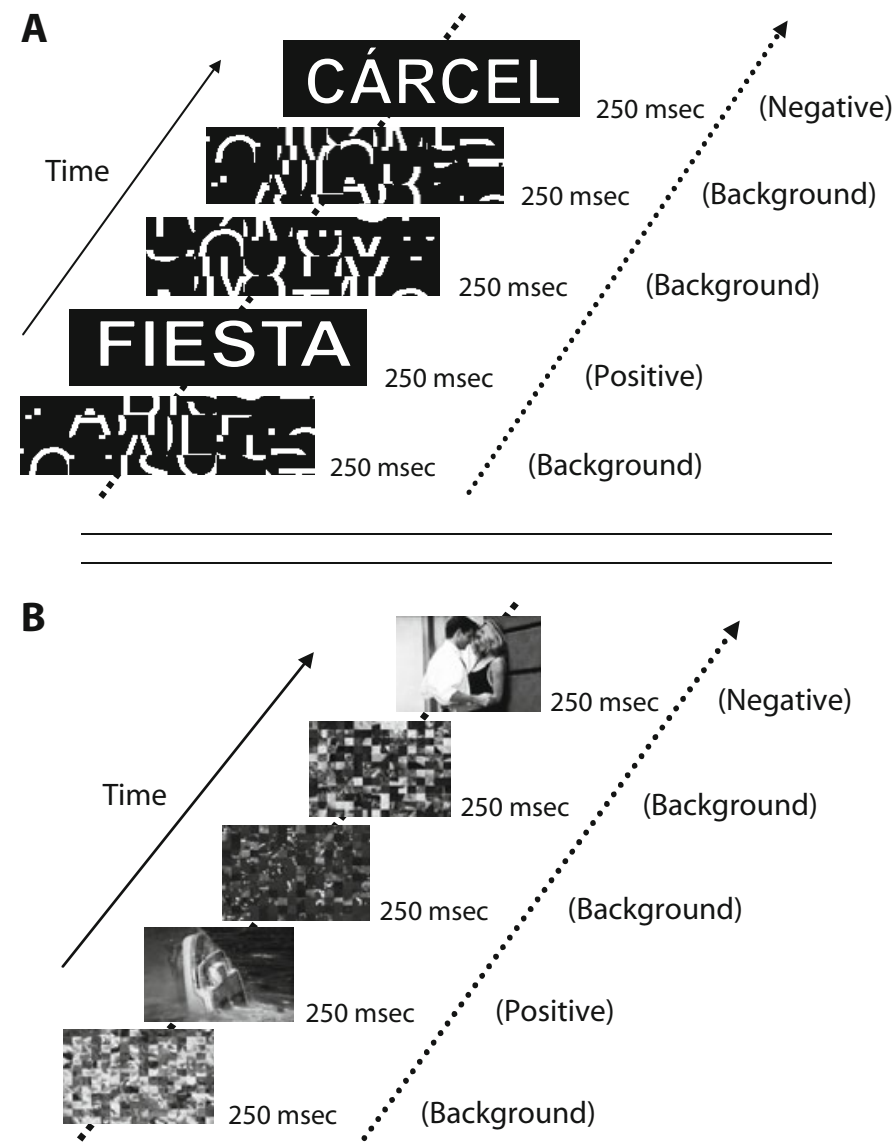

Figure 1. Schematic illustration of the stimulation paradigm for both experiments: (A) Experiment 1 (cárcel $=$ jail; fiesta $=$ party). (B) Experiment 2.

points for $-6-\mathrm{dB}$ octave roll-off) and a digitization sampling rate of $250 \mathrm{~Hz}$.

Data analysis. Trials with omissions and false alarms were excluded from the analyses. Also, those trials with RTs longer than $1,500 \mathrm{msec}$ or shorter than $200 \mathrm{msec}$ were not analyzed. Average ERPs from -200 to $800 \mathrm{msec}$ after the presentation of every type of test stimulus were computed separately. Those epochs with artifacts other than eye movements were removed after visual inspection. Offline correction of eye movement artifacts was made, using the method described by Semlitsch, Anderer, Schuster, and Presslich (1986). For the entire sample of electrodes, data originally M2referenced were rereferenced using the average of the mastoids.

Overall repeated measures ANOVAs were first performed to compare amplitudes between the ERP pattern elicited by positive, negative, neutral, and relaxing words. Amplitude was measured as the mean voltage within a particular time interval. To avoid the loss of statistical power when repeated measures ANOVAs are used to quantify a large number of electrodes (Oken \& Chiappa, 1986), 11 regions of interest were computed out of 58 electrodes. These regions are shown in Figure 2.

Three within-subjects factors were included in the ANOVA with the purpose of exploring possible topographic variation: affect type (four levels: positive words, negative words, neutral words, and relaxing words), anteriority (three levels: anterior, middle, and posterior), and laterality (three levels: left, middle, and right). Frontopolar and occipital regions were analyzed separately with the within-subjects factor of affect type. The Greenhouse-Geisser epsilon correction was applied in order to adjust the degrees of freedom of the $F$ ratios where necessary. In a second step and in order to explore possible interactions involving topographical factors, further ANOVAs were conducted for each particular region of interest, with affect type as a within-subjects factor. The $p$ values were adjusted to the Bonferroni correction for multiple comparisons. Finally, Bonferroni-corrected post hoc comparisons $(p<.05)$ were made for determining the significance of pairwise contrasts.

\section{Results}

Behavioral data. There were 3,200 epochs (40 averages for each of the 4 stimulus types in 20 subjects), and $7.4 \%$ were rejected because of artifacts, $0.7 \%$ because of false alarms, and $0.2 \%$ because of premature or delayed responses. Also excluded were those trials with omissions, which represented $1.2 \%$ for positive words, $1.1 \%$ for negative words, $1.3 \%$ for neutral words, and $0.9 \%$ for relaxing words. Table 2 displays the mean and standard deviation of the RTs for every stimulus condition. Mean RTs were $363 \mathrm{msec}$ for positive words, $359 \mathrm{msec}$ for negative words, $364 \mathrm{msec}$ for neutral words, and $365 \mathrm{msec}$ for relaxing words. Statistical analyses revealed that these differences were not significant $[F(3,57)=2.6$, $p>.05]$.

Electrophysiological data. Figure 3 illustrates the grand-averages corresponding to all types of test stimuli at every region of interest. A visual inspection of the grand-averaged ERPs revealed that effects were notice- 


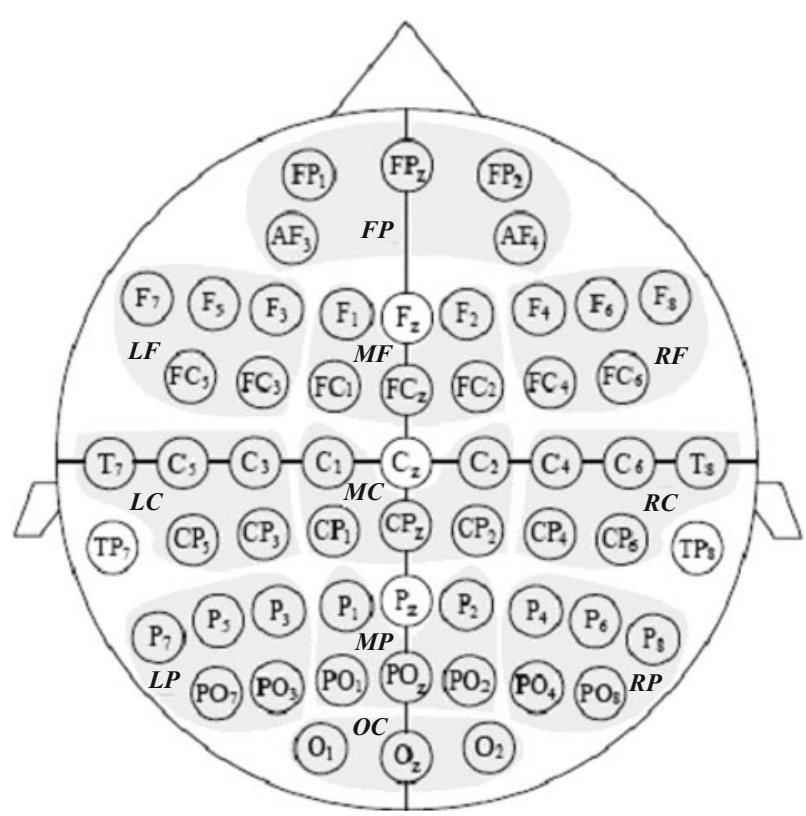

Figure 2. Scalp regions in which ERPs were grouped for statistical contrasts. FP, frontopolar, LF, left frontal; MF, middle central; RF, right frontal; $\mathrm{LC}$, left central; MC, middle central; $\mathrm{RC}$, right central; LP, left parietal; $\mathrm{CP}$, central parietal; RP, right parietal; OC, occipital.

able in two time windows. The first of these effects was a parieto-occipital negativity, peaking at about $250 \mathrm{msec}$, with a positive counterpart at frontal electrodes. The second effect was a parietal positivity with an onset of about $350 \mathrm{msec}$, with a negative counterpart at frontal electrodes. For statistical purposes, the amplitude of the early effect was measured in the 225- to 275 -msec time interval, and the amplitude of the parietal positivity in the 350 - to 425 -msec time interval. Table 2 shows amplitude means and standard deviations of these effects as a function of stimulus category.

225- to 275-msec effects. The results of the overall ANOVA showed no significant effects involving the factor of affect type. These results did not allow performing further analyses.

350- to 425-msec effects. The overall ANOVA revealed a significant effect for the affect type factor $[F(3,57)=$ $4.3, p<.05]$ and a statistical trend for the affect type $\times$ anteriority interaction $[F(6,114)=2.7, p<.1]$. Table 3 summarizes the results of the ANOVAs for each region of interest. They reached significance at the right-parietal $[F(3,57)=4.9, p<.01]$, frontopolar $[F(3,57)=2.9, p<$ $.05]$, and middle-frontal $[F(3,57)=3, p<.05]$ regions. Statistical trends were found at the occipital $[F(3,57)=$ $2.8, p<.1]$ and right-frontal $[F(3,57)=2.2, p<.1]$ regions. Differences between neutral and emotional stimuli that were evident at several regions of interest, as revealed by the post hoc analyses, are also reported in Table 3. Neutral words always showed larger amplitudes than did emotional words. The difference between negative words and neutral words reached significance at the occipital, rightparietal, right-frontal, and frontopolar regions. Similarly, positive and neutral words differed at the occipital, rightparietal, right-frontal, frontopolar, and middle-frontal regions. Finally, relaxing words differed from neutral words at the frontopolar region.

\section{Discussion}

The main finding of the first experiment was that neutral words elicited an enhancement of the amplitude of an LPC as compared with positive, negative, and relaxing words in the 350- to 425-msec time interval. No differences were noticeable in either an early negativity or RTs.

Regarding the absence of differences in the RTs, the results from the behavioral literature are rather inconsistent. Some studies have reported facilitation effects, whereas others have shown inhibition for emotional words (Carretié et al., 2008; Fazio, 2001; Kanske \& Kotz, 2007; Keil \& Ihssen, 2004; Rossell \& Nobre, 2004; Williamson, Harpur, \& Hare, 1991), using a variety of tasks, including Stroop, lexical decision, priming, and speed of pronunciation. Also, the results of some studies resemble our findings, since they have reported no effects at all (Klinger, Burton, \& Pitts, 2000; Spruyt, Hermans, Pandelaere, De Houwer, \& Eelen, 2004). Two explanations have been proposed for this lack of effects. First, some authors have pointed out that robust facilitation effects in behavioral tasks are observed only when subjects are required to categorize stimuli on the basis of their valence (Spruyt, De Houwer, Hermans, \& Eelen, 2007). Second, it has been suggested that facilitation effects may be diminished in tasks that require the processing of a high number of words in a short amount of time (Harris \& Pashler, 2004; Keil, 2006). Our findings support both views, since, in our experiment, words were presented at high rates of stimulation for short periods of time and the subjects were not asked to assess the emotional connotation of the stimuli.

A common finding of those studies that have presented words at high rates of stimulation has been the presence of a posterior negative deflection around $250 \mathrm{msec}$ (Hinojosa, Martín-Loeches, Muñoz, Casado, \& Pozo, 2004; Martín-Loeches, Hinojosa, Gómez-Jarabo, \& Rubia, 2001; Pulvermüller, 2001). This component has been related to early semantic processing - namely, lexical decision processes (Hinojosa, Martín-Loeches, \& Rubia, 2001) or word form analyses (Martín-Loeches, 2007). Recently, Kissler, Herbert, et al. (2007) have shown that these processes are modulated by the emotional connotation of words. Several studies have also revealed that the amplitude of an LPC is enhanced for negative and positive words (Kanske \& Kotz, 2007; Keil, Ihssen, \& Heim, 2006). This positivity has been thought to reflect an enhancement of top-down attention to the ongoing task (Cuthbert et al., 2000; Schupp et al., 2000).

Contrary to these findings, we found that the emotional content of the words did not modulate the early negativity and that both positive and negative words showed reduced amplitudes of the LPC, as compared with neutral stimuli. A number of reasons might account for this divergent pattern of results. First of all, interestingly, several studies have failed to report ERP differences between the 

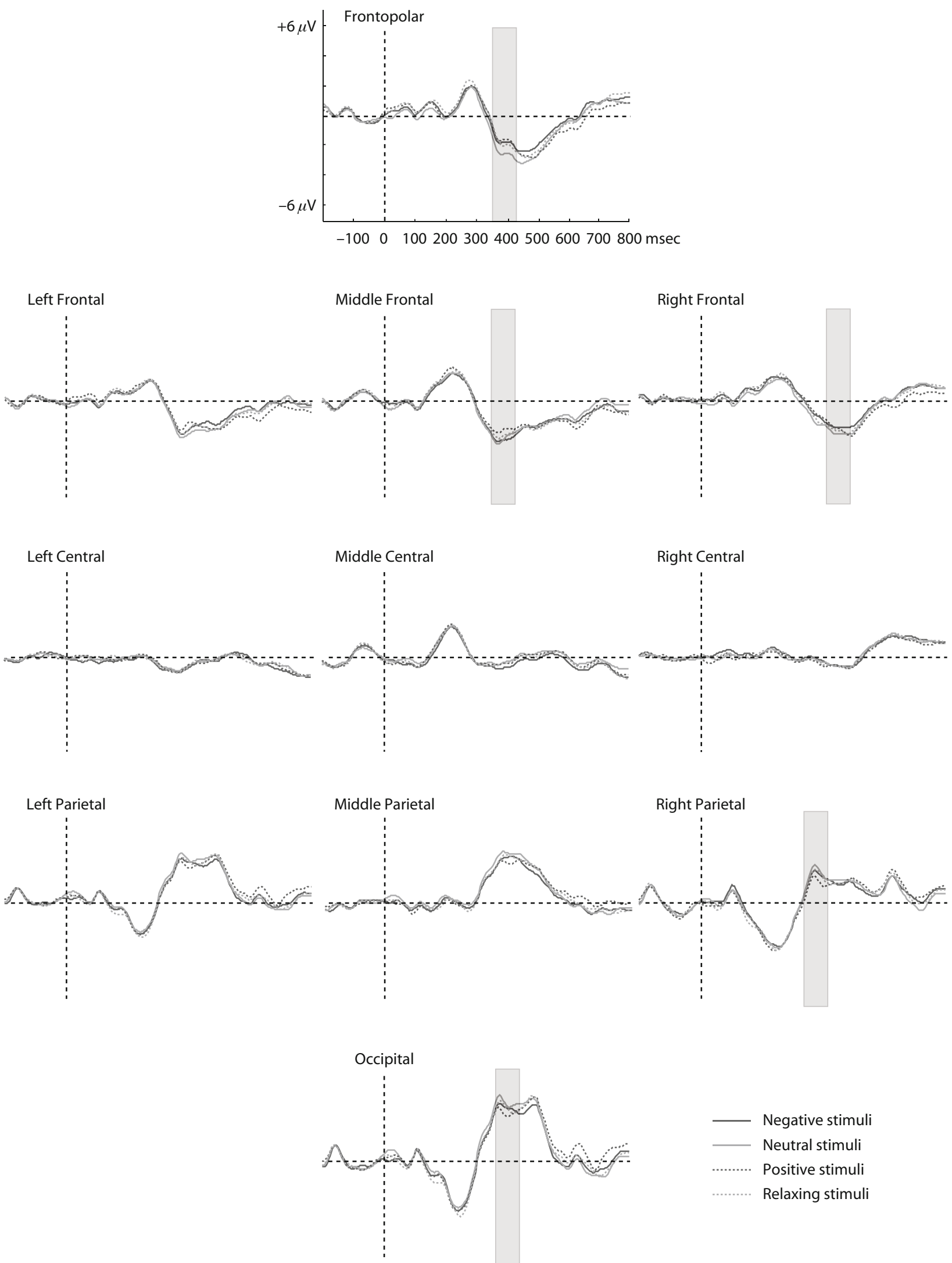

Figure 3. Grand-averaged ERPs elicited by negative, neutral, positive, and relaxing words at every region of interest. Scales are represented at the frontopolar region. 
Table 2

Means and Standard Deviations for Behavioral and

Electrophysiological Recordings for Words and Pictures

\begin{tabular}{|c|c|c|c|c|c|c|c|c|}
\hline & \multicolumn{2}{|c|}{ Negative } & \multicolumn{2}{|c|}{ Positive } & \multicolumn{2}{|c|}{ Neutral } & \multicolumn{2}{|c|}{ Relaxing } \\
\hline & $M$ & $S D$ & $M$ & $S D$ & $M$ & $S D$ & $M$ & $S D$ \\
\hline \multicolumn{9}{|c|}{ Words } \\
\hline Behavioral & & & & & & & & \\
\hline $\mathrm{RT}(\mathrm{msec})$ & 359.45 & 24.65 & 363.00 & 24.58 & 363.95 & 24.76 & 364.50 & 23.54 \\
\hline \multicolumn{9}{|l|}{ Electrophysiological } \\
\hline \multicolumn{9}{|c|}{225 - to 275 -msec amplitudes $(\mu \mathrm{V})$} \\
\hline Frontopolar & 1.27 & 1.28 & 1.25 & 1.62 & 1.03 & 1.40 & 1.64 & 1.70 \\
\hline Left frontal & 1.11 & 1.44 & 1.07 & 1.29 & 1.10 & 1.33 & 1.36 & 1.46 \\
\hline Middle frontal & 1.61 & 0.78 & 1.69 & 0.62 & 1.51 & 1.10 & 1.91 & 1.27 \\
\hline Right frontal & 1.64 & 0.83 & 1.49 & 0.90 & 1.21 & 1.24 & 1.63 & 1.23 \\
\hline Left central & -0.08 & 1.02 & 0.06 & 1.09 & 0.05 & 0.98 & 0.01 & 1.03 \\
\hline Middle central & 1.58 & 1.22 & 1.66 & 1.08 & 1.54 & 1.33 & 1.72 & 1.43 \\
\hline Right central & 0.63 & 0.90 & 0.38 & 0.89 & 0.34 & 0.96 & 0.42 & 0.92 \\
\hline Left parietal & -2.96 & 1.18 & -2.74 & 1.08 & -2.67 & 1.41 & -3.13 & 1.34 \\
\hline Middle parietal & -0.17 & 1.04 & -0.14 & 1.39 & 0.19 & 1.67 & -0.33 & 1.54 \\
\hline Right parietal & -2.86 & 1.45 & -2.99 & 1.33 & -2.80 & 1.25 & -3.15 & 1.55 \\
\hline Occipital & -3.36 & 1.65 & -3.25 & 1.59 & -2.87 & 1.85 & -3.79 & 2.09 \\
\hline \multicolumn{9}{|c|}{$350-$ to 425 -msec amplitudes $(\mu \mathrm{V})$} \\
\hline Frontopolar & -1.67 & 2.58 & -1.58 & 2.73 & -2.57 & 2.66 & -1.71 & 2.71 \\
\hline Left frontal & -1.90 & 2.36 & -1.80 & 2.21 & -2.44 & 2.35 & -2.13 & 2.13 \\
\hline Middle frontal & -2.63 & 2.19 & -2.16 & 1.88 & -2.94 & 2.13 & -2.67 & 2.03 \\
\hline Right frontal & -1.07 & 2.03 & -1.08 & 1.88 & -1.69 & 1.90 & -1.27 & 2.15 \\
\hline Left central & -0.67 & 1.21 & -0.62 & 0.97 & -0.63 & 0.97 & -0.85 & 0.93 \\
\hline Middle central & -0.54 & 1.88 & -0.32 & 1.80 & -0.30 & 2.15 & -0.46 & 1.88 \\
\hline Right central & -0.26 & 1.13 & -0.49 & 0.98 & -0.22 & 1.19 & -0.25 & 0.96 \\
\hline Left parietal & 2.83 & 1.90 & 2.62 & 1.49 & 3.19 & 1.44 & 2.79 & 1.85 \\
\hline Middle parietal & 3.01 & 2.35 & 2.89 & 2.46 & 3.55 & 2.60 & 3.18 & 2.69 \\
\hline Right parietal & 1.57 & 2.09 & 1.27 & 1.95 & 2.17 & 2.25 & 1.93 & 1.75 \\
\hline Occipital & 3.32 & 2.80 & 3.09 & 2.72 & 4.10 & 2.80 & 3.58 & 2.97 \\
\hline \multicolumn{9}{|c|}{ Pictures } \\
\hline Behavioral & & & & & & & & \\
\hline $\mathrm{RT}(\mathrm{msec})$ & 406.07 & 38.68 & 408.54 & 39.11 & 433.86 & 48.31 & 449.00 & 54.46 \\
\hline \multicolumn{9}{|l|}{ Electrophysiological } \\
\hline \multicolumn{9}{|c|}{ 175- to 275 -msec amplitudes $(\mu \mathrm{V})$} \\
\hline Frontopolar & 0.20 & 1.37 & 0.44 & 1.31 & -0.76 & 1.90 & -0.84 & 1.65 \\
\hline Left frontal & -0.46 & 1.11 & 0.14 & 1.35 & -0.63 & 1.50 & -0.37 & 1.16 \\
\hline Middle frontal & -0.30 & 1.13 & 0.16 & 1.31 & -0.72 & 1.03 & -0.56 & 1.17 \\
\hline Right frontal & 0.20 & 0.98 & 0.39 & 0.96 & -0.50 & 1.16 & -0.56 & 1.25 \\
\hline Left central & -0.42 & 0.66 & 0.08 & 0.78 & -0.07 & 0.80 & 0.20 & 0.66 \\
\hline Middle central & -0.11 & 0.91 & 0.36 & 1.23 & 0 & 1.16 & 0.07 & 1.10 \\
\hline Right central & 0.02 & 0.82 & -0.06 & 0.74 & -0.06 & 0.71 & -0.20 & 0.76 \\
\hline Left parietal & 0.37 & 1.34 & 0.32 & 1.53 & 1.12 & 1.21 & 1.19 & 1.34 \\
\hline Middle parietal & 0.58 & 1.41 & 0.40 & 1.36 & 1.05 & 1.59 & 0.86 & 1.47 \\
\hline Right parietal & 0.47 & 1.38 & -0.58 & 1.62 & 0.71 & 1.54 & 0.54 & 1.36 \\
\hline Occipital & -0.19 & 2.21 & -1.08 & 2.26 & 0.45 & 2.70 & 0.37 & 2.40 \\
\hline \multicolumn{9}{|c|}{$450-$ to 550 -msec amplitudes $(\mu \mathrm{V})$} \\
\hline Frontopolar & -3.39 & 2.50 & -3.17 & 2.95 & -2.65 & 2.91 & -1.86 & 2.69 \\
\hline Left frontal & -3.11 & 1.78 & -2.55 & 2.02 & -2.69 & 2.04 & -2.07 & 1.90 \\
\hline Middle frontal & -0.92 & 2.28 & -0.82 & 2.41 & -1.42 & 2.30 & -1.14 & 1.92 \\
\hline Right frontal & -2.08 & 2.22 & -2.02 & 2.43 & -1.44 & 2.02 & -1.20 & 1.85 \\
\hline Left central & -0.56 & 1.09 & -0.18 & 1.04 & -0.76 & 1.09 & -0.51 & 1.13 \\
\hline Middle central & 1.99 & 1.93 & 1.79 & 2.01 & 1.03 & 2.25 & 0.75 & 2.01 \\
\hline Right central & -0.03 & 1.00 & -0.18 & 1.21 & 0.20 & 1.05 & -0.01 & 1.14 \\
\hline Left parietal & 2.63 & 2.39 & 2.75 & 2.62 & 2.41 & 2.13 & 2.21 & 1.96 \\
\hline Middle parietal & 3.93 & 1.95 & 3.65 & 2.62 & 3.45 & 2.16 & 2.86 & 2.21 \\
\hline Right parietal & 1.37 & 1.86 & 0.82 & 2.00 & 1.50 & 2.07 & 1.00 & 1.80 \\
\hline Occipital & 2.96 & 2.79 & 2.65 & 3.03 & 2.92 & 2.83 & 2.27 & 2.59 \\
\hline
\end{tabular}

processing of emotional content and neutral words (Naumann et al., 1997; Vanderploeg et al., 1987). Some authors have attributed this result to task requirements. In this regard, when subjects are not explicitly instructed to perform an affective categorization of words, differences in the processing of emotional and neutral words disap- pear (Naumann et al., 1992; Naumann et al., 1997). Moreover, Fischler and Bradley (2006) have shown that effects of word emotionality on late positivities are consistently found when the task requires semantic processing of the words, but not otherwise. Finally, it has been suggested that word class might produce somewhat different effects 
Table 3

$F$ Values Corresponding to the ANOVAs Performed at Each Region of Interest in the 350- to 425-msec Time Window for Words, With the Results of the Post Hoc Bonferroni Analyses on These Contrasts

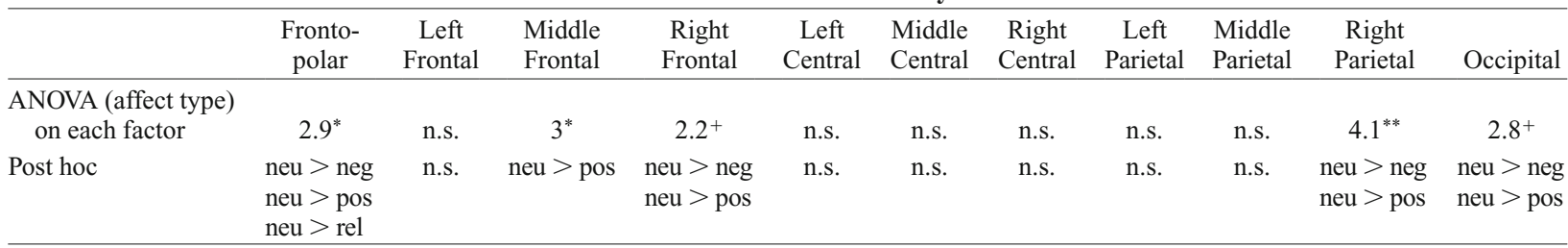

Note-Bonferroni analyses are reported by indicating the direction of the amplitude effect in those pairwise comparisons that reached significance $(p<.05)$. Neu, neutral words; neg, negative words; pos, positive words; rel, relaxing words; n.s., nonsignificant. $d f=3,57 . \quad{ }^{*} p<.05 . \quad{ }^{* *} p<$ $.01 . \quad+$ Statistical trend, $p<.1$.

(Kissler et al., 2006). For instance, Naumann et al. (1997) failed to replicate their previous findings (Naumann et al., 1992) of an enhancement of the amplitude of the LPC for emotional adjectives when they used nouns as stimuli. In our study, subjects were presented with nouns and had to perform a perceptual discrimination task that did not explicitly require either the affective categorization or the semantic processing of words. Therefore, all the abovementioned reasons might explain the lack of differences in the early negativity.

Although these arguments might also account in part for the enhancement of the amplitude of the LPC elicited by neutral, as compared with emotional, words, this result deserves further consideration. A possible explanation has to do with the proportion of neutral stimuli. In our task, most of the stimuli had no emotional valence (neutral and background stimuli), a situation that contrasts with other studies in which more emotional than neutral words have been presented (usually, two thirds emotional words and one third neutral words). Under these circumstances, words with emotional content could be more easily discriminated from background stimuli than could neutral words that shared the lack of emotional content with the background stimuli. It could be the case that the low percentage of emotional words made these stimuli not salient enough to disrupt the processing of the more frequent neutral stimuli, resulting in the enhancement of the LPC. In line with this argument, Naumann et al. (1997) found that differences between emotional and neutral words in the LPC vanished when the probability of occurrence of an emotional word diminished.

An alternative possibility is that since emotional stimuli were not able to attract additional attentional resources, the repetition of neutral stimuli (both neutral words and background) resulted in an enhanced LPC, due to an "emotional" repetition effect. Several studies have shown that these effects result in increased amplitudes of late positivities (e.g., Henson, Rylands, Ross, Vuilleumier, \& Rugg, 2004; Rugg, Mark, Gilchrist, \& Roberts, 1997).

In conclusion, the results of this experiment show that at least under some circumstances, the emotional connotation of words is not able to influence early processing. Moreover, it seems that at later stages of processing, attention is directed to those words that require more effort to be discriminated from stimuli that have a similar valence (neutral words from background stimuli). Consequently, it seems that the emotional content of words is not always able to influence language processing. In the following experiment, we tried to elucidate whether this would also be the case with pictures.

\section{EXPERIMENT 2}

\section{Method}

Subjects. Twenty-eight subjects ( 21 females), ranging in age from 19 to 29 years $(M=21.9)$, participated in this study as volunteers. All had normal or corrected-to-normal vision, and all were right-handed, according to the Edinburgh Handedness Inventory (Oldfield, 1971).

Stimuli. As in the first experiment, the stimuli consisted of 80 emotional stimuli ( 20 positive, 20 negative, 20 relaxing, and 20 neutral pictures) and 80 background stimuli. The reasons for selecting these four emotional categories were as explained previously. Emotional pictures were taken from the IAPS database (Lang, Bradley, \& Cuthbert, 2001). ${ }^{1}$ Background stimuli were made by randomly recombining portions of the 80 emotional pictures, resulting in nonsense images that resembled the physical attributes of the emotional pictures (color, brightness, etc.). Positive, negative, relaxing, and neutral pictures were chosen according to the same criteria as those followed in Experiment 1. As Table 1 illustrates, these criteria were also contrasted with one-way ANOVAs and post hoc analyses with the Bonferroni correction $(p<.05)$. Again, positive and negative pictures were matched in arousal and differed in valence. Relaxing pictures were matched to positive images in valence but differed in arousal and had different valence and arousal than did negative pictures. Finally, neutral pictures differed from the other picture types in both valence and arousal. Table 1 displays the mean valence and arousal for every emotional picture category.

As in Experiment 1, stimuli were presented black-on-white on a computer monitor, controlled by the Gentask module of the STIM2 package (NeuroScan Inc.).

Procedure. Figure 1B illustrates the stimulation procedure. The subjects were instructed to press a button as quickly as possible whenever they detected a meaningful image. The stimuli were presented according to the rapid stream stimulation (Hinojosa, MartínLoeches, et al., 2001; Rudell, 1992) in eight sequences. A practice sequence was also allowed. Each sequence contained 20 test stimuli ( 5 positive pictures, 5 negative pictures, 5 neutral pictures, and 5 relaxing pictures), together with the proportional amount of background stimuli. The stimuli were presented following the criteria described in the Procedure section in Experiment 1.

Data acquisition. Electroencephalographic recording procedures were exactly the same as in the first experiment, including the use of the same electrodes and the same parameters.

Data analysis. Data were analyzed in the same way as described in the Data analysis section of Experiment 1. 


\section{Results}

Behavioral data. There were 4,480 epochs (40 averages for each one of the 4 stimulus types in 28 subjects), and $6.2 \%$ were rejected because of artifacts, $0.5 \%$ because of false alarms, and $0.2 \%$ because of premature or delayed responses. Those trials with omissions, which represented $1.4 \%$ for positive pictures, $1.4 \%$ for negative pictures, $1.3 \%$ for neutral pictures, and $1.2 \%$ for relaxing pictures, were also excluded. Table 2 displays the mean and standard deviation of the RTs for every stimulus condition. Mean RTs were $409 \mathrm{msec}$ for positive pictures, $406 \mathrm{msec}$ for negative pictures, $433 \mathrm{msec}$ for neutral pictures, and $449 \mathrm{msec}$ for relaxing pictures. These differences were statistically significant $[F(3,81)=42.1, p<.001]$. Bonferroni post hoc analyses $(p<.05)$ revealed that RTs were shorter for positive pictures than for neutral pictures and relaxing pictures. RTs for negative pictures were also shorter than those for neutral and relaxing pictures. Finally, RTs for relaxing pictures were larger than those for neutral pictures.

Electrophysiological data. Figure 4 shows the waveforms for all stimulus types at every region of interest. Again, after a visual inspection of the grand averages, ERP effects were observed in two time windows: a parietooccipital negativity peaking at about $225 \mathrm{msec}$ with a positive counterpart at frontal electrodes and a parieto-occipital positivity with an onset of about $450 \mathrm{msec}$ and a negative counterpart at frontal electrodes. The amplitude of these effects was measured in the 175 - to $275-\mathrm{msec}$ and 450 - to 550 -msec time intervals, respectively, for statistical purposes. Table 2 displays amplitude means and standard deviations of these effects for every stimulus condition.

175- to 275-msec effects. The overall ANOVA reached significance for the affect type factor $[F(3,81)=4.4, p<$ $.05]$, and for the affect type $\times$ anteriority $[F(6,162)=10.8$, $p<.001]$, affect type $\times$ laterality $[F(6,162)=3.7, p<$ $.05]$, and affect type $\times$ anteriority $\times$ laterality $[F(12,324)=$ $4.8, p<.01]$ interactions. Table 4 shows the results of the ANOVAs conducted at each region of interest. The ANOVAs at each region of interest were significant at the occipital $[F(3,81)=11.2, p<.001]$, left-parietal $[F(3,81)=10.6$, $p<.001]$, right-parietal $[F(3,81)=19.9, p<.001]$, and right-frontal $[F(3,81)=10.3, p<.001]$ regions. Differences between high-arousal and low-arousal pictures, as revealed by the Bonferroni-corrected post hoc analyses, are also reported in Table 4. Positive pictures showed enhanced amplitudes, as compared with both neutral and relaxing pictures, at the occipital, left- and right-parietal, and rightfrontal regions. Also, positive pictures were associated with higher amplitudes than were negative pictures at the rightparietal and occipital regions.

Negative pictures elicited enhanced amplitude, as compared with both neutral and relaxing pictures, at the rightfrontal and left-parietal regions.

450- to 550-msec effects. The overall ANOVA revealed a significant effect in the affect type factor $[F(3,81)=$ $11.7, p<.001]$, the affect type $\times$ anteriority interaction $[F(6,162)=3.5, p<.05]$, the affect type $\times$ laterality interaction $[F(6,162)=9.8, p<.001]$, and the affect type $\times$ anteriority $\times$ laterality interaction $[F(12,324)=2.5, p<$ $.05]$. Table 4 summarizes the results of the ANOVAs for each region of interest and the post hoc analyses. The ANOVAs at each region of interest reached significance at the left-frontal $[F(3,81)=7.6, p<.001]$, right-frontal $[F(3,81)=4.5, p<.01]$, frontopolar $[F(3,81)=7.5, p<$ $.001]$, middle-central $[F(3,81)=16.5, p<.001]$, and middle-parietal $[F(3,81)=6.4, p<.01]$ regions. They revealed that positive pictures elicited higher amplitudes than did the neutral pictures at the middle-central region. Positive pictures also differed from relaxing stimuli at the frontopolar, right-frontal, middle-central, and middleparietal regions. Negative pictures elicited enhanced amplitudes, as compared with neutral images, at the middlecentral region. Finally, negative pictures were associated with higher amplitudes than were relaxing pictures at the frontopolar, left-frontal, middle-central, and middleparietal regions.

\section{Discussion}

Both behavioral and electrophysiological data show that the emotional information significantly modulated the processing of pictures. The results showed that positive and negative pictures elicited shorter RTs than did neutral pictures. Neutral stimuli elicited shorter RTs than relaxing pictures. Also, the activity of an early negativity and an LPC was influenced by the emotional content of pictures.

In line with previous literature (Calvo \& Nummenmaa, 2007; Öhman, Flykt, \& Esteves, 2001; Zhang, Lawson, Guo, \& Jiang, 2006), behavioral data suggest the existence of a guided by the level of arousal gradient, since stimuli that induced the highest levels of activation (negative and positive) showed the shortest RTs and those that induced the lowest amounts of activation (relaxing) showed the longest RTs.

Emotional content also modulated electrophysiological activity in an early negativity $(175-275 \mathrm{msec})$ at several scalp locations. Two main effects occurred during this period of time. First, a specific effect was observed for positive pictures that elicited enhanced amplitudes at right parieto-occipital electrodes, as compared with all other types of stimuli. Second, an arousal-dependent effect was observed at left parieto-occipital locations, since both positive and negative pictures showed larger amplitudes than did neutral and relaxing pictures. This effect replicates the findings of the studies that have presented pictures at high rates of stimulation (Junghöfer et al., 2001; Schupp et al., 2004; Schupp et al., 2007) and has been related to a privileged processing of emotional information in perceptual areas (Schupp et al., 2003; Schupp et al., 2007). Interestingly, Schupp et al. (2004) found an unexpected specific effect for positive pictures that differed from negative and neutral stimuli in the amplitude of this early negativity. The authors speculated on the possibility that this effect could be reflecting gender differences in affective processing, since all the subjects in their study were females. It seems that, as Schupp and collaborators' and our own data suggest, some brain circuits might be specifically en- 

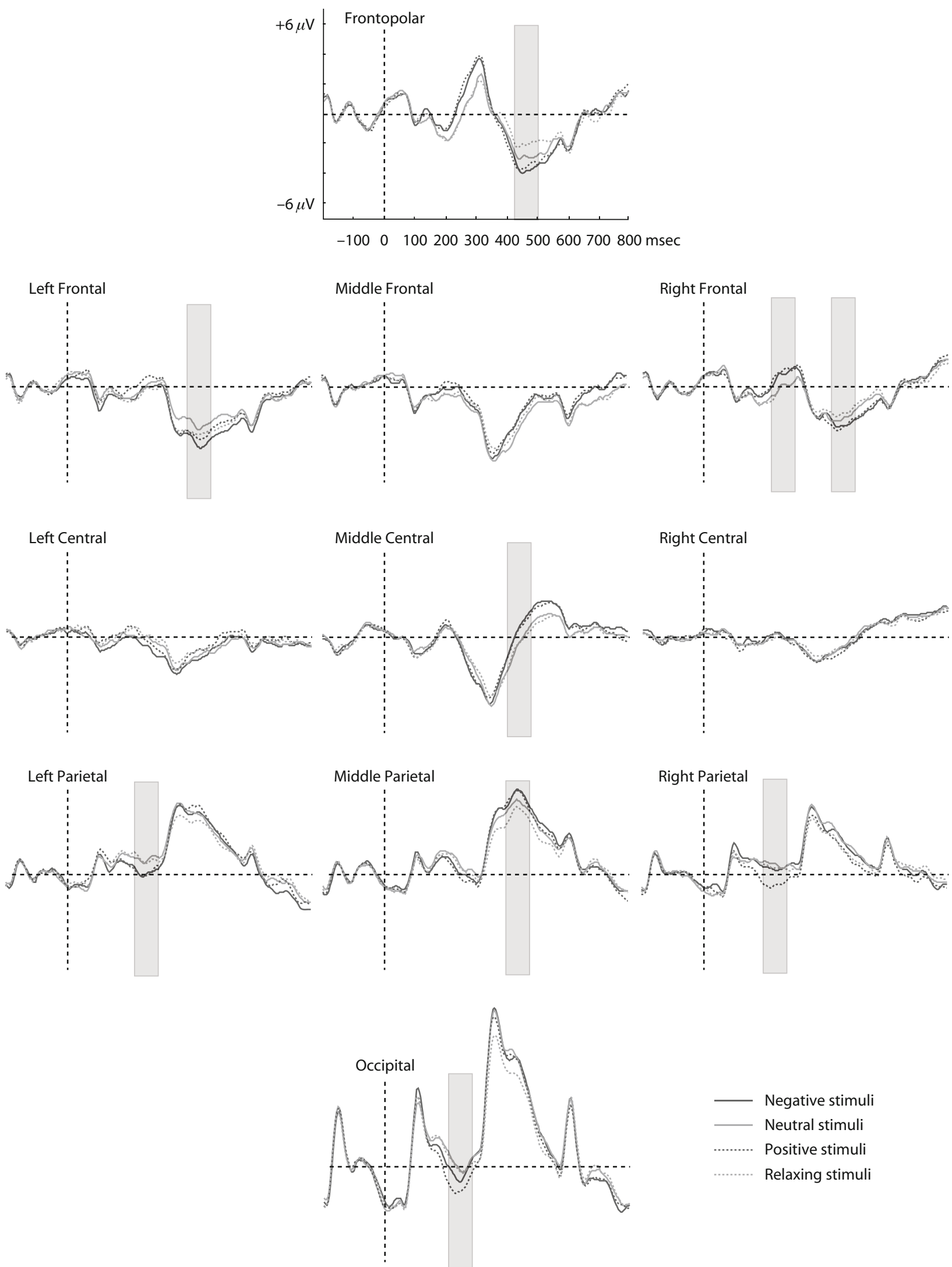

Neutral stimuli Positive stimuli Relaxing stimuli

Figure 4. Grand-averaged ERPs elicited by negative, neutral, positive, and relaxing pictures at every region of interest. Scales are represented at the frontopolar region. 
Table 4

F Values Corresponding to the ANOVAs Performed at Each Region of Interest in the 175- to 275-msec and the 450- to 550-msec Time Intervals for Pictures, With the Results of the Post Hoc Bonferroni Analyses on These Contrasts

\begin{tabular}{|c|c|c|c|c|c|c|c|c|c|c|c|}
\hline & $\begin{array}{l}\text { Fronto- } \\
\text { polar }\end{array}$ & $\begin{array}{c}\text { Left } \\
\text { Frontal }\end{array}$ & $\begin{array}{l}\text { Middle } \\
\text { Frontal }\end{array}$ & $\begin{array}{l}\text { Right } \\
\text { Frontal }\end{array}$ & $\begin{array}{c}\text { Left } \\
\text { Central }\end{array}$ & $\begin{array}{l}\text { Middle } \\
\text { Central }\end{array}$ & $\begin{array}{l}\text { Right } \\
\text { Central }\end{array}$ & $\begin{array}{c}\text { Left } \\
\text { Parietal }\end{array}$ & $\begin{array}{l}\text { Middle } \\
\text { Parietal }\end{array}$ & $\begin{array}{l}\text { Right } \\
\text { Parietal }\end{array}$ & Occipits \\
\hline \multicolumn{12}{|c|}{$175-275 \mathrm{msec}$} \\
\hline $\begin{array}{l}\text { ANOVA (affect type) } \\
\text { on each factor }\end{array}$ & n.s. & n.s. & n.s. & $10.3^{* * *}$ & n.s. & n.s. & n.s. & $10.6^{* * *}$ & n.s. & $19.9^{* * *}$ & $11.2^{* * *}$ \\
\hline Post hoc & n.s. & n.s. & n.s. & $\begin{array}{r}\text { pos }>\text { neu } \\
45\end{array}$ & $-550 \mathrm{~ms}$ & n.s. & n.s. & pos $>$ neu & n.s. & $\begin{array}{l}\text { pos }>\text { neu } \\
\text { pos }>\text { neg }\end{array}$ & $\begin{array}{l}\text { pos }>\mathrm{n} \\
\text { pos }>\mathrm{n}\end{array}$ \\
\hline $\begin{array}{l}\text { ANOVA (affect type) } \\
\text { on each factor } \\
\text { Post hoc }\end{array}$ & $\begin{array}{c}7.5^{* * *} \\
\operatorname{pos}>\text { rel }\end{array}$ & $\begin{array}{c}7.6^{* * *} \\
\operatorname{pos}>\text { rel }\end{array}$ & $\begin{array}{c}16.5^{* * *} \\
\text { pos }>\text { rel } \\
\text { pos }>\text { neu }\end{array}$ & $\begin{array}{c}4.5^{* *} \\
\text { pos }>\text { rel }\end{array}$ & $\begin{array}{l}\text { n.s. } \\
\text { n.s. }\end{array}$ & $\begin{array}{c}16.5^{* * *} \\
\text { pos }>\text { rel } \\
\text { pos }>\text { neu }\end{array}$ & $\begin{array}{l}\text { n.s. } \\
\text { n.s. }\end{array}$ & $\begin{array}{l}\text { n.s. } \\
\text { n.s. }\end{array}$ & $\begin{array}{l}6.4^{* *} \\
\text { n.s. }\end{array}$ & $\begin{array}{l}\text { n.s. } \\
\text { n.s. }\end{array}$ & $\begin{array}{l}\text { n.s. } \\
\text { n.s. }\end{array}$ \\
\hline
\end{tabular}

Note-Bonferroni analyses are reported by indicating the direction of the amplitude effect in those pairwise comparisons that reached significance $(p<.05)$. Neu, neutral pictures; neg, negative pictures; pos, positive pictures; rel, relaxing pictures; n.s., nonsignificant. $d f=3,81$. ${ }^{* *} p<$ $.01 . \quad * * * p<.001$.

gaged in the processing of positive information, as some recent fMRI studies have shown (Hamann \& Mao, 2002; Kensinger \& Schacter, 2006).

The emotional content of the pictures also influenced later stages of processing as indexed by an LPC in the 450- to 550 -msec time interval. Both positive and negative pictures elicited more enhanced amplitudes than did low-arousing pictures at centro-parietal and frontal electrodes. This result suggests a modulation of the amplitude of the LPC according to the level of arousal, which is similar to what occurs with RTs. Similar findings have been also reported in previous studies (Cuthbert et al., 2000; Delplanque, Lavoie, Hot, Silvert, \& Sequeira, 2004; Olofsson \& Polich, 2007). These differences have been interpreted as reflecting the engagement of the attentional system in a more complete processing of affective stimuli (Carretié, Martín-Loeches, Hinojosa, \& Mercado, 2001; Cuthbert et al., 2000; Schupp et al., 2007). Consequently, it seems that the processing of high-arousing emotional pictures is able to attract top-down modulated attention that reflects the activation of motivational systems in the brain even when they are embedded in a stream of nonrecognizable stimuli.

\section{Comparison Between Experiments 1 and 2}

In order to allow a direct comparison between the ERPs elicited by words and pictures, Figure 5 illustrates a selection of those regions of interest in which differences between emotional categories were more evident. In addition, Figure 6 shows the topographic distribution of the early and late effects in both words and pictures and for each emotional stimulus after subtracting the activity elicited by neutral stimuli.

The brain activity corresponding to the two ERP components elicited by words and pictures in all the emotional conditions was subjected to an ANOVA. This analysis included the within-subjects factors of affect type (four levels), anteriority (three levels), and laterality (three levels) and the between-subjects factor of stimulus type (two factors: words and pictures). Only the interactions involving the affect type and stimulus type factors were relevant for the purposes of this study. Additional ANOVAs involving the within-subjects factor of affect type (four levels) and the between-subjects factor of stimulus type (two factors) were carried out in each region of interest in order to better characterize these interactions whenever found. Finally, in those regions of interest that showed significant interactions between affect type and stimulus type, Bonferroni corrected $(p<.05)$ pairwise tests comparing every emotional word category with its picture counterpart were carried out (i.e., negative words vs. negative pictures, neutral words vs. neutral pictures, and so on). This procedure was an attempt to explore the possibility that the differences observed between words and pictures were due to an effect confined to a particular emotional category.

In the early component, significant results were found for the affect type $\times$ anteriority $\times$ stimulus type $[F(6,276)=$ $4.8, p<.01]$ and affect type $\times$ anteriority $\times$ laterality $\times$

Table 5

$F$ Values Corresponding to the ANOVAs Performed at Each Region of Interest in the Early and Late Effects for the Comparison of Words and Pictures

\begin{tabular}{ccccccccccr}
$\begin{array}{c}\text { Fronto- } \\
\text { polar }\end{array}$ & Left & Middle & Right & Left & Middle & Right & Left & Middle & Right & \\
Frontal & Frontal & Frontal & Central & Central & Central & Parietal & Parietal & Parietal & Occipital \\
\hline
\end{tabular}

Early Effect

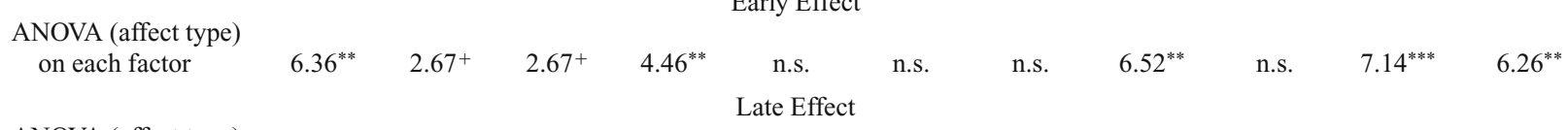

ANOVA (affect type)

on each factor

$5.74^{* *} \quad 4.12^{* *} \quad$ n.s. $5.11^{* *} \quad$ n.s. $9.17^{* *}$

n.s. $\quad$ n.s. $\quad 4.53^{* *}$

n.s.

n.s.

Note-Only the relevant results of the interaction between the affect type and stimulus type factors are shown. n.s., nonsignificant. $d f=$

3,138. ${ }^{* *} p<.01 .{ }^{* * *} p<.001 . \quad+$ Statistical trend, $p<.1$. 

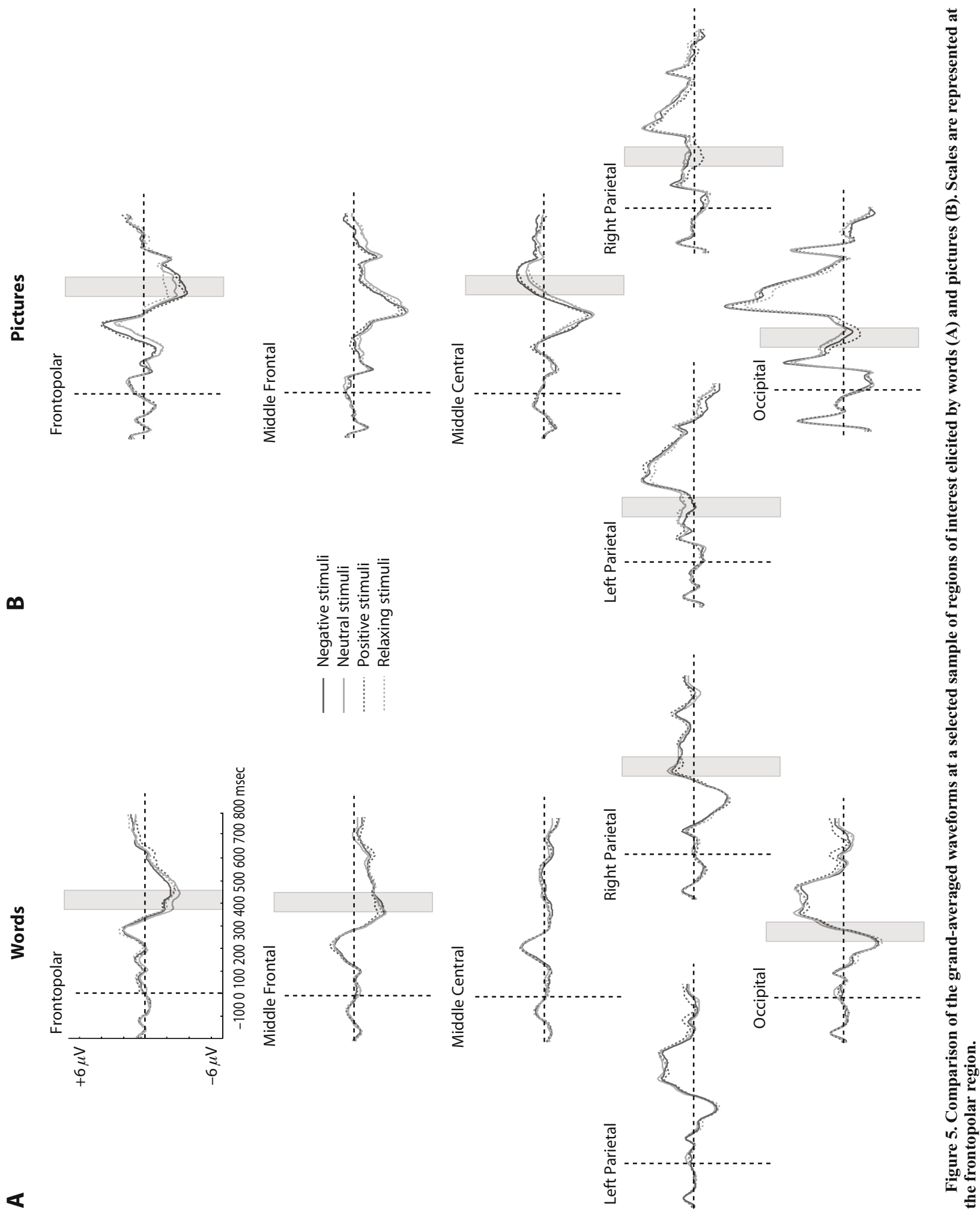
A

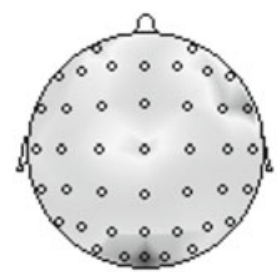

Positive - Neutral

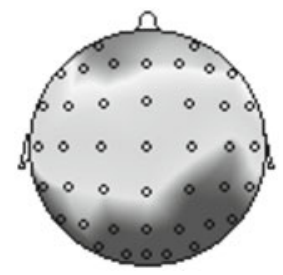

Positive - Neutral

\section{Words}

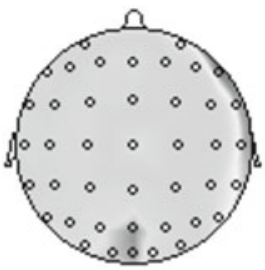

Negative - Neutral

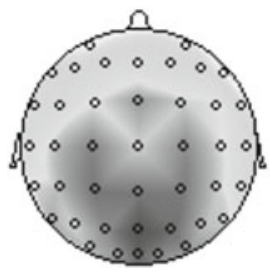

Negative - Neutral

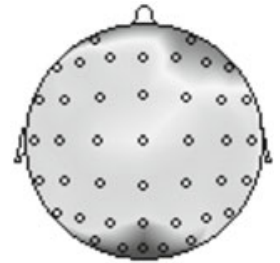

$0.4 \mu \mathrm{V}$

225-275 msec

$-0.4 \mu \mathrm{V}$

Relaxing - Neutral

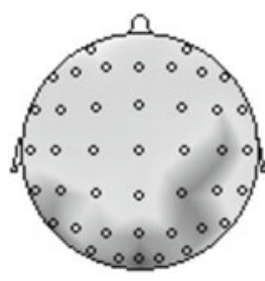

Relaxing - Neutral
B

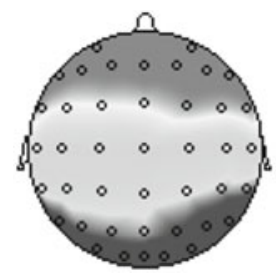

Positive - Neutral
Pictures

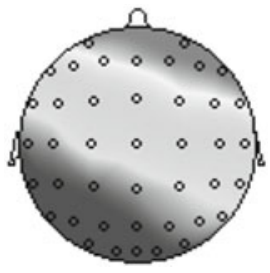

Negative - Neutral

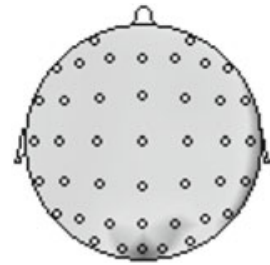

Relaxing - Neutral
$1 \mu \mathrm{V}$

350-425 msec

$-0.5 \mu \mathrm{V}$

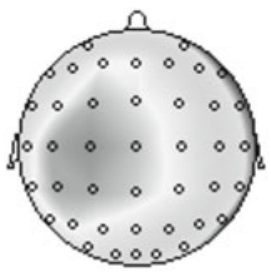

Positive - Neutral

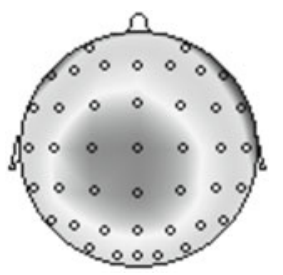

Negative - Neutral

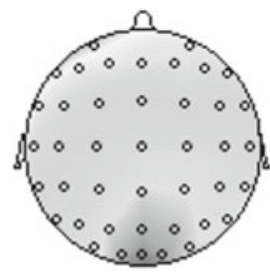

Relaxing - Neutral
$1.1 \mu \mathrm{V}$

175-275 msec

$-0.8 \mu \mathrm{V}$

$1.2 \mu \mathrm{V}$

450-550 msec

$-1 \mu \mathrm{V}$

Figure 6. Topographic difference maps of the distribution of the early posterior negativity and the late positive component for every word and emotion picture category. The activity associated to neutral stimuli has been subtracted from the activity elicited by affective stimuli.

stimulus type $[F(12,552)=2.1, p<.05]$ interactions. A statistical trend was observed for the interaction between affect type and stimulus type $[F(6,162)=3.7, p<.1]$. Table 5 summarizes the results of these analyses. The ANOVAs conducted at each region of interest reached significance at the occipital $[F(3,138)=6.3, p<.01]$, left-parietal $[F(3,138)=6.5, p<.01]$, right-parietal $[F(3,138)=7.1$, $p<.001]$, right-frontal $[F(3,138)=4.5, p<.01]$, and frontopolar $[F(3,138)=6.4, p<.01]$ regions. A statistical trend was found at the left-frontal $[F(3,138)=2.7$, $p<.1]$ and middle-frontal $[F(3,138)=2.7, p<.1]$ regions.
Post hoc analyses conducted in those regions in which the affect type $\times$ stimulus type interaction reached significance showed that negative, positive, neutral, and relaxing words differed from negative, positive, neutral, and relaxing images at the same regions (occipital, left- and right-parietal, left-, middle-, and right-frontal, and frontopolar locations).

The amplitude of the late component showed differences as a function of the stimulus type, reflected in the significant affect type $\times$ stimulus type $[F(3,138)=7, p<.001]$, affect type $\times$ anteriority $\times$ stimulus type $[F(6,276)=3.3$, $p<.05]$, and affect type $\times$ laterality $\times$ type of stimuli 
$[F(6,276)=3.9, p<.01]$ interactions. As can be appreciated in Table 5, the interaction between affect type and type of stimuli was significant in several regions of interest. It was significant at left-frontal $[F(3,138)=4.1, p<$ $.01]$, right-frontal $[F(3,138)=5.1, p<.01]$, frontopolar $[F(3,138)=5.7, p<.01]$, middle-central $[F(3,138)=$ $9.2, p<.001]$, and middle-parietal $[F(3,138)=4.5, p<$ $.01]$ regions. The results of the post hoc analyses indicated that negative, positive, neutral, and relaxing words and pictures differed at middle-central electrodes. Also, the difference between negative words and pictures was significant at the frontopolar and left-frontal regions.

\section{GENERAL DISCUSSION}

The results of this study showed that the processing of emotional information operated in a different way for words and pictures even under equivalent experimental circumstances in which no explicit semantic processing was required. Differences were evident at both behavioral and electrophysiological levels and indicated that affective information modulated the processing of pictures and had little influence in word processing. Several authors have previously suggested that stimuli that are relevant from a biological point of view, such as emotional images, are capable of inducing higher amounts of physiological arousal in the viewer than are verbal emotional material whose emotional meaning is acquired by learning (Keil, 2006; Kissler et al., 2006; Mogg \& Bradley, 1998; Vanderploeg et al., 1987). However, such a suggestion has been based mainly on indirect data. Our study now provides direct electrophysiological evidence supporting this view.

\section{Reaction Times}

A first difference in the processing of emotional aspects of words and pictures emerged in the pattern of RTs. A clear influence of the arousal dimension is noticeable in the case of pictures. In this regard, positive and negative high-arousing pictures elicited shorter RTs as compared with neutral, mildly arousing pictures and low-arousing relaxing images. No differences were apparent between arousal categories in the case of words. This finding is also in agreement with the results of the study by De Houwer and Hermans (1994). These authors reported differences in several behavioral measures, including interference effects and naming times, between the processing of emotional and neutral pictures, but not between emotional and neutral words. Taken together, these data support the claim that there is a different access to affective information by words and pictures (Fiske \& Pavelchak, 1986).

\section{ERP Data}

Differences in the processing of affective information between words and pictures were even more evident in the pattern of ERPs. Despite the existence of some differences in the processing of words and pictures, due to the fact that activating an emotional network via lexical information is different from object recognition (for de- tailed discussions of this issue, see Caramazza, 1996; Hinojosa, Martín-Loeches, Gómez-Jarabo, \& Rubia, 2000; Keil, 2006; Martín-Loeches, 2007), the processing of both words and pictures was associated with two similar components in our study: an early posterior negativity and an LPC.

Emotional pictures elicited an enhancement of the amplitude of a posterior negativity between 175 and $275 \mathrm{msec}$ after the stimulus presentation. However, there were no differences between affective categories, even if a narrow time window from 225 to $275 \mathrm{msec}$ was considered. Differences between words and pictures were more evident at frontal and parieto-occipital electrodes. Several studies have shown facilitation for the processing of affective information at early stages reflected by similar negativities for either words (Kissler, Herbert, \& Junghöfer, 2007) or pictures (Junghöfer et al., 2001). However, the results of our study suggest that whereas this advantage is consistent for pictorial information, it cannot be generalized for verbal information. This finding could account for the results of those studies that failed to report early modulations by emotional information during word processing (e.g., Naumann et al., 1997; Vanderploeg et al., 1987) and suggests that special care should be taken when approaching the study of emotion using words as stimuli. The different modulation of the early negativity by words and pictures supports those theoretical perspectives that postulate a functional segregation of the access to affective information for this type of stimuli and fits well with the idea of a privileged access of images to emotional information (Bower, 1981; Fiske \& Pavechak, 1986).

The processing of emotional information also differed between words and pictures at later stages, as reflected by the different modulation of the LPC, a component that is thought to reflect the functional mobilization of attentional resources in affective processing (Delplanque et al., 2006). High-arousing pictures elicited larger amplitudes than did low-arousing images, whereas neutral words elicited larger amplitudes than did emotional words. Such differences were especially evident at frontal and centro-parietal scalp regions and suggest that attention was engaged differently in the processing of pictorial and verbal affective information. It seems that it was task compromised in the case of words, facilitating the processing of those stimuli that were more difficult to discriminate (see the Discussion section of Experiment 1). By contrast, attentional engagement was emotionally driven in the case of pictures, facilitating the processing of those stimuli that are more relevant from a biological perspective (see the Discussion section of Experiment 2). These results now provide direct evidence supporting the view that emotional images are capable of inducing a higher amount of physiological arousal than are affective words, as has previously been suggested (Carretié et al., 2008; Keil, 2006).

Another difference refers to the fact that LPC effects were noticeable at different time windows, from 350 to $425 \mathrm{msec}$ for words and from 450 to $550 \mathrm{msec}$ for pictures. Several studies have reported LPC effects at different time windows for the affective processing of either 
words (Dillon et al., 2006; Herbert et al., 2006; Kanske \& Kotz, 2007) or pictures (Huang \& Luo, 2006; Keil et al., 2002; Schupp et al., 2007), ranging from 200 to $800 \mathrm{msec}$. The results of some of these studies are favorable to there being a temporal advantage for the processing of words, whereas others show that pictures are processed earlier. However, the existence of serious divergences in the experimental procedures does not allow establishing whether emotional words or pictures are processed more quickly. Under the same experimental conditions, our data show that LPC effects for words precede those reflecting picture processing. Several reasons could account for this discrepancy. For pictures, it might be the case that subsequent facilitated processing reflected by the LPC does not occur until previous facilitation effects in the access to affective information at early stages of processing (as reflected by the early negativity) have been resolved. Since this previous facilitation did not occur for words, the processes indexed by the LPC could be triggered earlier than in the case of pictures. Alternatively, this difference might be related to the distinct nature of the engagement of attention (in a task-driven way for words vs. an emotiondriven fashion for pictures).

It should be remarked that in addition to affective significance, the LPC is sensitive to stimulus probability and rate of target occurrence (Polich, 2007; Rosenfeld, Biroschak, Kleschen, \& Smith, 2005). Although LPC amplitude might be reduced in rapid serial presentation paradigms (Schupp et al., 2007), stimulus probability appears unlikely to explain the differential LPC findings for words and pictures in this study. Above all, the target/ nontarget ratio was the same, at least for positive, negative, and relaxing stimuli. However, relaxing stimuli did not show different LPC effects, as compared with either emotional words or pictures. Furthermore, even though stimulus probability for all the categories was the same in both experiments, the results were quite the opposite.

\section{Conclusion}

Our data suggest that emotional information exerts a different influence on the processing of pictures, as compared with the processing of words, in accordance with some theoretical proposals (Bower, 1981; Fiske \& Pavelchak, 1986). This seems to be true at least when stimuli have to be processed quickly, without focusing the attention on their emotional or semantic content, and when they are embedded in a stream of nonemotional stimuli. It has been suggested that emotional stimuli need to exceed a critical threshold value before they are able to capture attention (Koster, Crombez, Van Damme, Verschuere, \& De Houwer, 2004; Mogg \& Bradley, 1998). Several factors have been claimed to influence this threshold. Among them, the level of involvement in the ongoing cognitive task seems to play a crucial role (Schwartz et al., 2005). Also, it has been pointed out that emotional stimuli are not insensitive to some regulatory influences, including inhibition effects due to sensory competition or high attentional load (Lavie, 2005; Vuilleumier, 2005). Our results are in accordance with these views by showing that, under some circumstances, those emotional stimuli that are not as biologically prepared as others might not always be able to surpass the threshold and attract attention.

\section{AUTHOR NOTE}

This work was supported by Grant SEJ2005-08461-C02-01/PSIC from the Ministerio de Educación y Ciencia of Spain. Correspondence concerning this article should be addressed to J. A. Hinojosa, Instituto Pluridisciplinar, Universidad Complutense de Madrid, 28040 Madrid, Spain (e-mail: hinojosa@pluri.ucm.es).

\section{REFERENCES}

Alameda, J. R., \& Cuetos, F. (1995). Diccionario de frecuencias de las unidades lingüisticas del castellano. Oviedo: Universidad de Oviedo.

Bower, G. H. (1981). Mood and memory. American Psychologist, 36, 129-148.

Bradley, M. M., \& Lang, P. J. (2007). Emotion and motivation. In J. T. Cacioppo, L. G. Tassinary, \& G. G. Berntson (Eds.), Handbook of psychophysiology (3rd ed., pp. 581-607). Cambridge: Cambridge University Press.

Calvo, M. G., \& Nummenmaa, L. (2007). Processing of unattended emotional visual scenes. Journal of Experimental Psychology: General, 136, 347-369.

Caramazza, A. (1996). Pictures, words and the brain. Nature, 383, 216217.

Carretié, L., Hinojosa, J. A., Albert, J., López-Martín, S., DE la Gándara, B. S., IgOA, J. M., \& Sotillo, M. (2008). Modulation of ongoing cognitive processes by emotionally intense words. Psychophysiology, 45, 188-196.

Carretié, L., Hinojosa, J. A., Albert, J., \& Mercado, F. (2006). Neural response to sustained affective visual stimulation using an indirect task. Experimental Brain Research, 174, 630-637.

Carretié, L., Hinojosa, J. A., Martín-Loeches, M., Mercado, F., \& TAPIA, M. (2004). Automatic attention to emotional stimuli: Neural correlates. Human Brain Mapping, 22, 290-299.

Carretié, L., Iglesias, J., García, T., \& Ballesteros, M. (1997). N300, P300 and the emotional processing of visual stimuli. Electroencephalography \& Clinical Neurophysiology, 103, 298-303.

Carretié, L., Martín-Loeches, M., Hinojosa, J. A., \& Mercado, F. (2001). Emotion and attention interaction studied through event-related potentials. Journal of Cognitive Neuroscience, 13, 1109-1128.

Cuthbert, B. N., Schupp, H. T., Bradley, M. M., Birbaumer, N., \& LANG, P. J. (2000). Brain potentials in affective picture processing: Covariation with autonomic arousal and affective report. Biological Psychology, 52, 95-111.

De Houwer, J., \& Hermans, D. (1994). Differences in the affective processing of words and pictures. Cognition \& Emotion, 8, 1-20.

Delplanque, S., Lavoie, M. E., Hot, P., Silvert, L., \& Sequeira, H. (2004). Modulation of cognitive processing by emotional valence studied through event-related potentials in humans. Neuroscience Letters, 356, 1-4.

Delplanque, S., Silvert, L., Hot, P., Rigoulot, S., \& Sequeira, H. (2006). Arousal and valence effects on event-related P3a and P3b during emotional categorization. International Journal of Psychophysiology, 60, 315-322.

Dillon, D. G., CoOper, J. J., Grent-'T-Jong, T., WoldorfF, M. G., \& LABAR, K. S. (2006). Dissociation of event-related potentials indexing arousal and semantic cohesion during emotional word encoding. Brain \& Cognition, 62, 43-57.

FAZIO, R. H. (2001). On the automatic activation of associated evaluations: An overview. Cognition \& Emotion, 15, 115-141.

Fazio, R. H., Sanbonmatsu, D. M., Powell, M. C., \& Kardes, F. R. (1986). On the automatic activation of attitudes. Journal of Personality \& Social Psychology, 50, 229-238.

Fischler, I., \& BRAdLey, M. M. (2006). Event-related potential studies of language and emotion: Words, phrases, and task effects. Progress in Brain Research, 156, 185-203. 
Fiske, S. T., \& PavelchaK, M. A. (1986). Category-based versus piecemeal-based affective responses: Developments in schematriggered affect. In R. M. Sorrentino \& E. T. Higgins (Eds.), Handbook of motivation and cognition (pp. 167-203). New York: Wiley.

Glaser, W. R. (1992). Picture naming. Cognition, 42, 61-105.

Glaser, W. R., \& Glaser, M. O. (1989). Context effects on Stroop-like word and picture processing. Journal of Experimental Psychology: General, 118, 13-42.

Hamann, S., \& MaO, H. (2002). Positive and negative emotional verbal stimuli elicit activity in the left amygdala. NeuroReport, 13, 15-19.

Harris, C. R., \& Pashler, H. (2004). Attention and the processing of emotional words and names: Not so special after all. Psychological Science, 15, 171-178.

Henson, R. N., Rylands, A., Ross, E., Vuilleumier, P., \& RugG, M. D. (2004). The effect of repetition lag on electrophysiological and haemodynamic correlates of visual object priming. NeuroImage, 21, 1674-1689.

Herbert, C., Kissler, J., Junghöfer, M., Peyk, P., \& Rockstroh, B. (2006). Processing of emotional adjectives: Evidence from startle EMG and ERPs. Psychophysiology, 43, 197-206.

Hinojosa, J. A., Martín-Loeches, M., Casado, P., Muñoz, F., FERnández-Frías, C., \& Pozo, M. A. (2001). Studying semantics in the brain: The rapid stream stimulation paradigm. Brain Research Protocols, 8, 199-207.

Hinojosa, J. A., Martín-Loeches, M., Gómez-Jarabo, G., \& Rubia, F. J. (2000). Common basal extrastriate areas for the semantic processing of words and pictures. Clinical Neurophysiology, 111, 552-560.

Hinojosa, J. A., Martín-Loeches, M., Muñoz, F., Casado, P., \& Pozo, M. A. (2004). Electrophysiological evidence of automatic early semantic processing. Brain \& Language, 88, 39-46.

Hinojosa, J. A., Martín-Loeches, M., \& Rubia, F. J. (2001). Eventrelated potentials and semantics: An overview and an integrative proposal. Brain \& Language, 78, 128-139

HuAnG, Y.-X., \& LUO, Y.-J. (2006). Temporal course of emotional negativity bias: An ERP study. Neuroscience Letters, 398, 91-96.

Junghöfer, M., Bradley, M. M., Elbert, T. R., \& Lang, P. J. (2001). Fleeting images: A new look at early emotion discrimination. Psychophysiology, 38, 175-178.

KANSKE, P., \& Kotz, S. A. (2007). Concreteness in emotional words: ERP evidence from a hemifield study. Brain Research, 1148, 138-148.

KeIL, A. (2006). Macroscopic brain dynamics during verbal and pictorial processing of affective stimuli. Progress in Brain Research, 156, 217-232.

Keil, A., Bradley, M. M., Hauk, O., Rockstroh, B., Elbert, T. [R.], \& LANG, P. J. (2002). Large-scale neural correlates of affective picture processing. Psychophysiology, 39, 641-649.

KeIL, A., \& IHsSEN, N. (2004). Identification facilitation for emotionally arousing verbs during the attentional blink. Emotion, 4, 23-35.

KeIL, A., Ihssen, N., \& HeIm, S. (2006). Early cortical facilitation for emotionally arousing targets during the attentional blink. BMC Biology, 4, 23.

Kensinger, E. A., \& Schacter, D. L. (2006). Processing emotional pictures and words: Effects of valence and arousal. Cognitive, Affective, \& Behavioral Neuroscience, 6, 110-126.

Kissler, J., Assadollahi, R., \& Herbert, C. (2006). Emotional and semantic networks in visual word processing: Insights from ERP studies. Progress in Brain Research, 156, 147-183.

Kissler, J., Herbert, C., \& Junghöfer, M. (2007). Attention and emotion in visual word processing: An ERP study [Abstract]. Psychophysiology, 44, S37.

Kissler, J., Herbert, C., Peyk, P., \& Junghöfer, M. (2007). Buzzwords: Early cortical responses to emotional words during reading. Psychological Science, 18, 475-480.

Klinger, M. R., Burton, P. C., \& Pitts, G. S. (2000). Mechanisms of unconscious priming: I. Response competition, not spreading activation. Journal of Experimental Psychology: Learning, Memory, \& Cognition, 26, 441-455.

Koster, E. H. W., Crombez, G., Van Damme, S., Verschuere, B., \& De Houwer, J. (2004). Does imminent threat capture and hold attention? Emotion, 4, 312-317.

Lang, P. J., Bradley, M. M., \& Cuthbert, B. N. (1998). Motivated attention: Affect, activation, and action. In P. J. Lang, R. F. Simons, \&
M. T. Balaban (Eds.), Attention and orienting: Sensory and motivational processes (pp. 97-135). Mahwah, NJ: Erlbaum.

Lang, P. J., Bradley, M. M., \& Cuthbert, B. N. (2001). International affective picture system (IAPS): Instruction manual and affective ratings (Tech. Rep. A-5). Gainesville: University of Florida, Center for Research in Psychophysiology.

Lavie, N. (2005). Distracted and confused?: Selective attention under load. Trends in Cognitive Sciences, 9, 75-82.

Martín-Loeches, M. (2007). The gate for reading: Reflections on the recognition potential. Brain Research Reviews, 53, 89-97.

Martín-Loeches, M., Hinojosa, J. A., Gómez-Jarabo, G., \& Rubia, F. J. (2001). An early electrophysiological sign of semantic processing in basal extrastriate areas. Psychophysiology, 38, 114-124.

Mogg, K., \& Bradley, B. P. (1998). A cognitive-motivational analysis of anxiety. Behaviour Research \& Therapy, 36, 809-848.

Naumann, E., Bartussek, D., Diedrich, O., \& Laufer, M. E. (1992). Assessing cognitive and affective information processing functions of the brain by means of the late positive complex of the event-related potential. Journal of Psychophysiology, 6, 285-298.

Naumann, E., Maier, S., Diedrich, O., Becker, G., \& Bartussek, D. (1997). Structural, semantic, and emotion-focused processing of neutral and negative nouns: Event-related potential correlates. Journal of Psychophysiology, 11, 158-172.

Öhman, A., Flykt, A., \& Esteves, F. (2001). Emotion drives attention: Detecting the snake in the grass. Journal of Experimental Psychology: General, 130, 466-478.

Oken, B. S., \& Chiappa, K. H. (1986). Statistical issues concerning computerized analysis of brainwave topography. Annals of Neurology, 19, 493-497.

OldFIELD, R. C. (1971). The assessment and analysis of handedness: The Edinburgh inventory. Neuropsychologia, 9, 97-113.

Olofsson, J. K., Nordin, S., Sequeira, H., \& Polich, J. (2008). Affective picture processing: An integrative review of ERP findings. Biological Psychology, 77, 247-265.

Olofsson, J. K., \& Polich, J. (2007). Affective visual event-related potentials: Arousal, repetition, and time-on-task. Biological Psychology, 75, 101-108.

Polich, J. (2007). Updating P300: An integrative theory of P3a and P3b. Clinical Neurophysiology, 118, 2128-2148.

Pulvermüller, F. (2001). Brain reflections of words and their meaning. Trends in Cognitive Sciences, 5, 517-524.

Rosenfeld, J. P., Biroschak, J. R., Kleschen, M. J., \& SMith, K. M. (2005). Subjective and objective probability effects on P300 amplitude revisited. Psychophysiology, 42, 356-359.

Rossell, S. L., \& Nobre, A. C. (2004). Semantic priming of different affective categories. Emotion, 4, 354-363.

RUDELL, A. P. (1992). Rapid stream stimulation and the recognition potential. Electroencephalography \& Clinical Neurophysiology, 83, 77-82.

RugG, M. D., Mark, R. E., Gilchrist, J., \& Roberts, R. C. (1997). ERP repetition effects in indirect and direct tasks: Effects of age and interitem lag. Psychophysiology, 34, 572-586.

Schapkin, S. A., Gusev, A. N., \& Kunl, J. (2000). Categorization of unilaterally presented emotional words: An ERP analysis. Acta Neurobiologiae Experimentalis, 60, 17-28.

Schupp, H. T., Cuthbert, B. N., Bradley, M. M., Cacioppo, J. T., Ito, T., \& LANG, P. J. (2000). Affective picture processing: The late positive potential is modulated by motivational relevance. Psychophysiology, 37, 257-261.

Schupp, H. T., Junghöfer, M., Weike, A. I., \& Hamm, A. O. (2003). Emotional facilitation of sensory processing in the visual cortex. Psychological Science, 14, 7-13.

Schupp, H. T., Junghöfer, M., Weike, A. I., \& Hamm, A. O. (2004). The selective processing of briefly presented pictures: An ERP analysis. Psychophysiology, 41, 441-449.

Schupp, H. T., Stockburger, J., Codispoti, M., Junghöfer, M., Weike, A. I., \& Hamm, A. O. (2007). Selective visual attention to emotion. Journal of Neuroscience, 27, 1082-1089.

Schwartz, S., Vuilleumier, P., Hutton, C., Maravita, A., Dolan, R. J., \& Driver, J. (2005). Attentional load and sensory competition in human vision: Modulation of fMRI responses by load at fixation during task-irrelevant stimulation in the peripheral visual field. Cerebral Cortex, 15, 770-786. 
Semlitsch, H. V., Anderer, P., Schuster, P., \& Presslich, O. (1986). A solution for reliable and valid reduction of ocular artifacts, applied to the P300 ERP. Psychophysiology, 23, 695-703.

Spruyt, A., De Houwer, J., Hermans, D., \& Eelen, P. (2007). Affective priming of nonaffective semantic categorization responses. Experimental Psychology, 54, 44-53.

Spruyt, A., Hermans, D., Pandelaere, M., De Houwer, J., \& Eelen, P. (2004). On the replicability of the affective priming effect in the pronunciation task. Experimental Psychology, 51, 109-115.

VANDERPloeg, R. D., Brown, W. S., \& Marsh, J. T. (1987). Judgments of emotion in words and faces: ERP correlates. International Journal of Psychophysiology, 5, 193-205.

Vuilleumier, P. (2005). How brains beware: Neural mechanisms of emotional attention. Trends in Cognitive Sciences, 9, 585-594.

Williamson, S., Harpur, T. J., \& Hare, R. D. (1991). Abnormal processing of affective words by psychopaths. Psychophysiology, 28, 260-273.
Zhang, Q., Lawson, A., Guo, C., \& Jiang, Y. (2006). Electrophysiological correlates of visual affective priming. Brain Research Bulletin, 71, 316-323.

\section{NOTE}

1. Positive images: $1710,2160,2216,2345,4599,4607,4608,4641$, 4652, 4660, 4670, 4680, 5480, 5621, 5623, 8034, 8370, 8400, 8470, 8501; negative images: $3101,3220,3230,3500,3550,6250,6570.1,7920$, 9050, 9181, 9300, 9410, 9420, 9600, 9620, 9635.1, 9800, 9910, 9911, 9921; neutral images: $1935,2410,2575,5395,5455,5531,5532,5533$, $5535,7491,7495,7496,7500,7504,7510,7560,7620,7820,7830,9472$; relaxing images: $1604,1610,1900,1910,2304,2370,2388,5000,5001$, 5010, 5020, 5030, 5200, 5551, 5720, 5750, 5760, 5800, 5811, 5870.

(Manuscript received May 8, 2008; revision accepted for publication November 3, 2008.) 